\title{
¿Qué es el encarnizamiento terapéutico?
}

\author{
What is dysthanasia?
}

D urante el XL Congreso Internacional de Cirugía General, realizado recientemente en la ciudad de Mérida, en varios cursos, conferencias y simposios se utilizó la expresión "Encarnizamiento terapéutico" la cual no siempre está de acuerdo con el pensamiento de los oyentes, ni representa el concepto que el conferencista quiere transmitir. El Diccionario del uso del español de María Moliner define el encarnizamiento como furia, apasionamiento o crueldad con la que se insiste en un daño, por lo que la expresión es poco afortunada, peyorativa y ofensiva, ya que en los actos terapéuticos del médico y del cirujano, a pesar de que en ocasiones pueden ser molestos o peligrosos, no existe la intención de causar daño. El cirujano y el equipo de salud siempre tratan de ayudar al enfermo, curarlo, aliviarlo o consolarlo, por lo que la palabra encarnizamiento está fuera de lugar.

Por lo antes expuesto se prefieren las expresiones "obstinación terapéutica" o "empecinamiento terapéutico" que indican persistencia o terquedad en la aplicación de medidas terapéuticas extraordinarias, las cuales pueden beneficiar a algunos enfermos, pero en otros son "fútiles" al no proporcionar ningún beneficio. Por lo que en cada paciente en particular se debe valorar el costo-beneficio de los procedimientos y medicamentos aplicados, no dejar de usar lo estrictamente necesario y las medidas ordinarias de la medicina paliativa, encaminadas a suprimir el dolor y el sufrimiento, pero tampoco empecinarse en la realización de todos los procedimientos que la ciencia y la tecnología pone a nuestra disposición, en la aplicación de todos los medicamentos de la farmacopea actual, cuando la valoración clínica y los índices pronósticos sugieren que en nada ayudan al enfermo. Con ello se evita el mal llamado encarnizamiento terapéutico, del que poco se puede esperar, en contraste con el costo, molestias y peligro para el enfermo.

En el enfermo terminal, con un pronóstico de sobrevida no mayor de seis meses, como consecuencia de una enfermedad neoplásica, progresión de una enfermedad crónico-degenerativa o complicaciones de un padecimiento agudo, la aplicación de medidas extraordinarias o desproporcionadas se conoce como "distanasia", neologismo que indica desviación de la muerte natural o esperada, según la historia natural del padecimiento. El evitar el empecinamiento terapéutico en estos enfermos corresponde a la "adistanasia" en la que se suprimen las medias desproporcionadas, con ello tácitamente se está aceptando una eutanasia pasiva, en la cual se dejan de aplicar medidas fútiles y el enfermo fallece como consecuencia de la enfermedad o complicaciones que sufre.

Procedimientos como la intubación endotraqueal, respiración asistida, nutrición parenteral, aplicación de múltiples medicamentos, antibióticos y la misma cirugía, en muchos enfermos evitan una muerte prematura, 
ayudan a la recuperación de la salud y la rehabilitación del enfermo; sin embargo, en aquellos enfermos con un tumor maligno avanzado, con importante deterioro como consecuencia de una enfermedad crónicodegenerativa, complicaciones de una intervención quirúrgica que lo han llevado a insuficiencia órgano funcional múltiple resistente al tratamiento instituido, en quienes la valoración clínica y los índices pronósticos indican que el enfermo no es recuperable, el persistir en la realización de procedimientos invasores y aplicación de muchos medicamentos, que en nada benefician al paciente, Ilevan a la obstinación terapéutica que más que evitar una muerte prolongan una agonía.

Después de una valoración clínica completa se debe elegir el manejo más apropiado para cada enfermo en particular, continuar con las medidas ordinarias o proporcionadas orientadas a suprimir el dolor, síntomas molestos y el sufrimiento, como son: acompañamiento, aseo, movilización, hidratación, curación de heridas y estomas, pero suspender los procedimientos de los que ya no se espera ningún beneficio, como pueden ser: quimioterapia, radioterapia y la misma cirugía en enfermos con neoplasias malignas avanzadas y metástasis múltiples, al igual que medidas de sostén respiratorio, nutricional, cardiovascular, renal o hematológico en enfermos con padecimientos benignos con complicaciones quirúrgicas o de la misma enfermedad, que los han llevado a un estado de deterioro severo, con insuficiencia órgano funcional resistente al tratamiento instituido.

Es común la crítica a un médico o un cirujano que se empecina en utilizar todos los medios a su alcance para "salvar" a un enfermo moribundo, que no reconoce que el paciente ha llegado al final de su ciclo vital, lo que hace por apasionamiento en su profesión, por soberbia al luchar obstinadamente con una muerte inevitable, por su desmedido interés en las actividades asistenciales, académicas, de investigación y en raras ocasiones por interés económico, olvidándose que lo más importante siempre es el enfermo. Corresponde al médico y al cirujano la decisión de continuar o no con un tratamiento intensivo, lo que también es motivo de crítica, si lo suspende se le acusa de abandonar al enfermo y si lo continúa sin razón cae en el empecinamiento terapéutico. El médico decide si continúa o no con las medidas de sostén, sobre la vida y posible muerte del enfermo a su cargo, por lo que no es raro que se diga que "Está jugando a ser Dios", por lo que todas las decisiones se deben tomar de acuerdo con los deseos del paciente, la opinión de la familia o la persona responsable y en algunas ocasiones del Comité de Bioética Hospitalario.

El mal llamado encarnizamiento terapéutico debe evitarse, es un terreno resbaloso que no tiene límites precisos, por lo que se requiere una valoración integral del enfermo, las consultas necesarias y, en caso de requerirlo, una decisión colegiada para aplicar en cada enfermo en particular el manejo más adecuado, siempre con solidaridad y un sentido humanista.

Dr. César Gutiérrez Samperio E-mail: cesargtzsamp@prodigy.net.mx, cegusa@uaq.mx 